These charts were calibrated to correspond with the calibration of the instrument.

\title{
Results SATISFACTORY.
}

The three spectroscopes referred to above and mounted as described have been in use continuously and at the present time are still in perfect working order. Some distinct advantages have been demonstrated.

1. The spectroseope is made readily portable and no darkened room required. It can readily be taken into the laboratory and kept under supervision and direction of the instruetor.

2. Corrosion by laboratory fumes is reduced to a minimum.

3 . Once the spectroseope is adjusted, tampering by inexperienced students is prevented.

4. With the instrument near at hand the students are more inclined to familiarize themselves with its use and advantages.

\section{THE VALUE OF FREQUENT TESTING.}

By Charles H. Sampson.

Huntington School, Boston, Mass.

Not so very long ago (the practice is still in vogue in some schools) pupils were ranked very largely on the work which they passed in for correction. This method of determining a grade for any and all abilities has changed for the better in most of our preparatory institutions. It is well that the change has taken place both for the school and for the student.

Work outside the class is often well and conscientiously done. On the other hand, there are always a few among us who seem to have been placed on earth to spoil the good intentions of the many and to grade a student because of what his home work indicates is very often an injustice in a class because a poor student and a good student receive an equal grade. Grading on the basis of grades received in frequent tests is by far the most satisfactory and most just to all concerned.

Tests should be given weekly in all subjects that are scheduled for every day. They should cover the work that has been covered during the preceding week. These examinations should be short but the questions should be selected with great care and they should aim to bring out of the mind of the student an understanding of some important principle. The making out of a test is not the matter of a few moments' time nor of the careless selection of problems or questions. A question should not be asked merely to obtain an answer but rather to determine the weaknesses that may exist in one's knowledge of any given subject. If the faults are known there can usually be a remedy. 
It is not necessary that tests be given at any particular time but it is better if some fairly close system be followed. If possible, tests should be given at convenient stopping points, such as at the end of a chapter, etc.

It has been said that men are ereatures of habit. This trait exhibits itself in the matter of testing as elsewhere. Boys and girls are no exception to this rule, even though they have not reached maturity. In fact, there is no better time in life to form good habits. Becoming accustomed to frequent testing is an excellent habit for all young people to form who expect to go to college. It will do no harm to those who do not expect to advance educationally.

There is another exceedingly important reason why preparatory school students should welcome the opportunity to be frequently tested. This reason is not fully realized during the progress through the course but when the college examinations are close enough at hand to make one begin to feel nervous and uncomfortable the good points of the reason will be evident. If frequent testing has been the rule, there will not be the usual apprehension and fear that grips one previous to attempting the ordeal which most of those who enter college are obliged to undergo. Nothing could be more ideal than for one to go up to the college entrance examinations as he would go to one of his frequent tests. It is true that one of the prime causes of failure in these examinations is that which we call "getting rattled." Frequently, brilliant students fail because of this confusion. Frequent testing will do much to eradicate this evil.

The time may come when entrance to college will be universally decided by other means than by written examination. The College Entrance Examination Board is still doing a big business, however, and will no doubt so continue to do for a long time to come. As long as this situation is as it is let us not under-rate the value to be derived from frequent testing.

Incidentally, it may be said that there are other values to be derived from frequent testing that are of great benefit to the individual himself, as he progresses through college. No boy or girl can successfully encounter a series of frequent tests without forming very valuable habits of industry and study. And who will say that such habits as these will not be of great value in any future undertaking be it in advanced school work or in the life work that one may choose to enter? 